\title{
Testing a Dynamic Complex Hypothesis in the Analysis of Land Use Impact on Lake Water Quality
}

\author{
QingHai Guo $\cdot$ KeMing Ma $\cdot$ Liu Yang $\cdot$ Kate He
}

Received: 10 November 2008 / Accepted: 7 August 2009 /

Published online: 18 August 2009

(C) Springer Science+Business Media B.V. 2009

\begin{abstract}
In this study, we proposed a dynamic complex hypothesis that the impact of land use on water quality could vary along the expansion of the buffer size, and there should be an effective buffer zone where the strongest linkage occurs between land use and water quality. The hypothesis was tested and supported by a case study carried out in four watersheds in Hanyang District, China. More specific, buffer analysis and regression model were applied for studying the impacts of land use type, area proportion of land use type, and spatial pattern of land use on water quality. We conclude that not only the proportion of land use but also the spatial pattern moderates the impact of land use on water quality. Our study indicates that the identification of the effective buffer zones can provide new information and ideas for planning and management. Moreover, this study could also partially help to explain the conflicting results on the impact of land use on water quality in buffer versus in catchments in the literatures.
\end{abstract}

Keywords Spatial pattern • Effective buffer • Land use • Water quality • Hanyang District • China

Q. Guo $\cdot$ K. Ma $(\bowtie)$

State Key Laboratory of Urban and Regional Ecology,

Research Center for Eco-Environmental Sciences, Chinese Academy of Sciences,

Beijing, 100085, China

e-mail:mkm@rcees.ac.cn

Q. Guo

e-mail: qhguo@iue.ac.cn

L. Yang

School of Resource and Safety Engineering,

China University of Mining and Technology (Beijing),

Beijing, 100083, China

K. He

Department of Biological Sciences, Murray State University, Murray, KY 42071, USA 


\section{Introduction}

The degradation of water quality is a key global environmental issue that needs urgent attention (Palmer et al. 2004). Studies have suggested that water degradation could be caused by two general sources: the point sources which typically include household or industrial wastewater and wastewater treatment plants (Kim et al. 2005), and the non-point sources (NPS) represented by the runoff from urban area and farmland (Leitch and Harbor 1999; Wang 2001). It is evident in recent years that urbanization has been one of the leading anthropogenic activities causing the destruction of natural ecosystems in China due to its thriving economy. The continued replacement of vegetative surface has made the rainfall, which once filtered through soil, now flow through storm drains and discharges directly into streams and coastal areas. As a result of rapid urbanization, the water quality degrades quickly and extensively (Changnon and Demissie 1996; Mander et al. 1998; Palmer et al. 2004; Conway and Lathrop 2005).

Research has studied the impact of land use on water quality by spatial analysis, statistical analysis, and hydrologic modeling (Mattikalli and Richards 1996; Hanratty and Stefan 1998; Rai and Sharma 1998; Tsihrintzis and Hamid 1998; Brezonik and Stadelmann 2002; Chang 2008; Amiri and Nakane 2009). A strong relationship between land use and water quality within catchments or watersheds has been suggested by previous studies (Gburek and Folmar 1999; Brezonik and Stadelmann 2002; Ha and Stenstrom 2003; Donohue et al. 2006; Moreno et al. 2006). Land use, in many cases, has been one of the key-contributing factors for urban water pollution (Changnon and Demissie 1996; Mander et al. 1998; Foley et al. 2005; Grimm et al. 2008). For example, urban and agricultural land uses have shown positive relationship with NPS loads; on the other hand, orchard and grassland contribute to NPS loads negatively (Basnyat et al. 1999; Wang 2001; Tong and Chen 2002; Moreno et al. 2006).

While a strong linkage has been suggested between land use and water quality at the catchments or watershed scale (Wang 2001; Tong and Chen 2002; Moreno et al. 2006), a number of studies have shown conflicting results on the impact of land use on water quality in buffers versus in catchments. For example, Johnson et al. (1997) found that the whole catchments explained slightly less of the water quality variability than that in the $100 \mathrm{~m}$ buffer. Similar analysis of land use data by Sawyer et al. (2004) showed that agricultural practices and urbanization occurring within $30 \mathrm{~m}$ buffer of the stream had higher correlations to biotic community structure than that at the catchments. Conversely, Sliva and Williams (2001) used multiple regressions to show that land use characteristics at the catchment scale had slightly greater influence on water quality than that in the $100 \mathrm{~m}$ buffer. Lastly, Hunsaker and Levine (1995) found that the relationship between land use and water quality was distinctly stronger at catchments scale than that in the 200 or $400 \mathrm{~m}$ buffer. The inconsistent results can be attributed to a number of factors, such as different characteristics of study regions, inconsistent parameters of water quality used in each study, and low resolution of digitized data (Sliva and Williams 2001). We also should point out that most previous studies focusing on the relationship between land use and water quality were only carried out in one buffer and catchments. However, the complexity and variability in spatial pattern and the trend of impacts of land uses on water quality have not been explored. 
In general, the greater the percentage of land use significantly and negatively related to water quality, the more the loads of total nitrogen, total phosphorus, and other water quality parameters are present in water bodies (Mehaffey et al. 2005). Whereas, the greater the percentage of land use positively to water quality, the lower the loads of water quality parameters (Basnyat et al. 1999). Within a watershed, some land use forms act as NPS source and others function as sink. In addition, land use patterns are spatially heterogeneous in general. During storm water runoff, NPS pollutants delivered from NPS sources can be absorbed, deposited, and re-separated out on different land use types. This process is a multi-step, often episodic (Phillips 1989). Therefore, we proposed the dynamic complex hypothesis that the impact of land use on water quality could vary along the expansion of the buffer size, and that there should be an effective buffer zone where the strongest linkage occurs between land use and water quality. When beyond or under the effective buffer zone, the impact of land use on water quality should become weak or insignificant (Fig. 1), given that the land use characteristics themselves varied with distance.

In this study, we applied the principle of landscape ecology, which highlights the strong link between pattern and process (Gustafson 1998), to study the relationship between land use and water quality. Our objectives are: (1) to explain that water quality is an integrated result of positive and negative influences of land uses, (2) to quantify how much the influence of spatial pattern of land use on the surface water quality (Gillies et al. 2003), and (3) to test the dynamic complex hypothesis. We used buffer analysis and pattern analysis techniques to investigate the correlation of land

Fig. 1 Sketch of the relationship between land uses and water quality parameters. a The trends in positive or negative influence of land uses on water quality along the gradient of percentage of land use. $\mathbf{b}$ The effect of integrated land use on water quality along the gradient of buffer width; '—- delegates the strongest effect within a buffer width, and '-....-' delegates the similar effect in different buffer width. Noting: the percentage of land use and buffer width both are in a fixed studying region
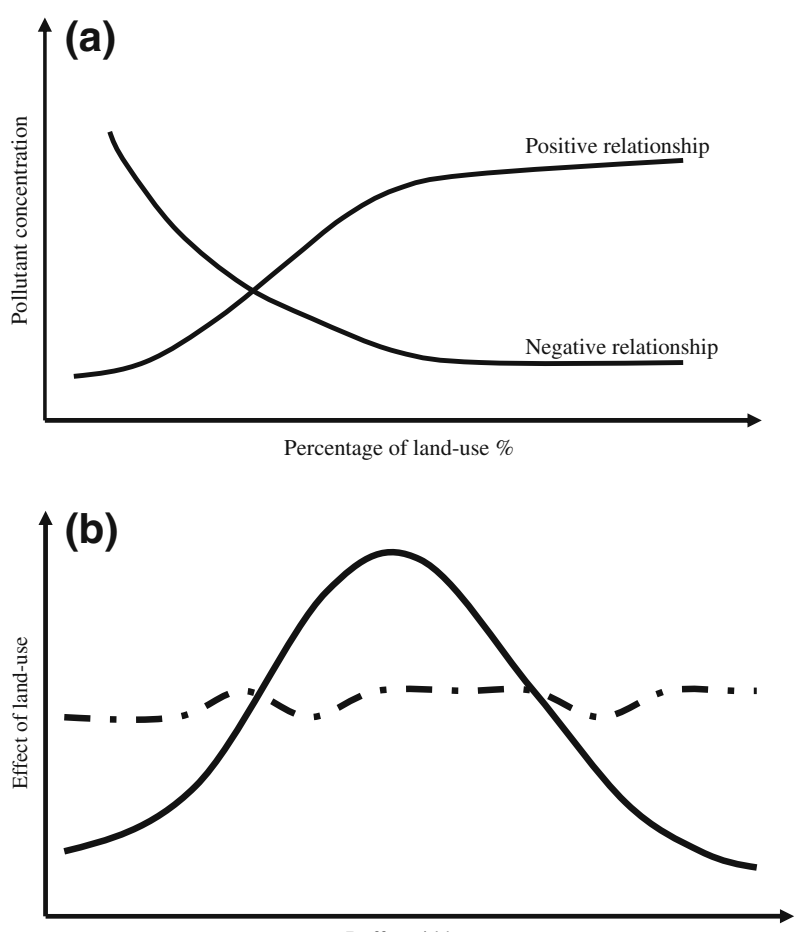

Buffer width 
uses with water quality in watershed varied with buffer distance along lakeshores by a stepwise regression model.

\section{Materials and Methods}

We selected four watersheds in Hanyang District in southern China (Fig. 2) as our study regions because they illustrate the process of the rapid urbanization and ecological and environmental problems caused by the urban growth during the past two decades. A previous study done by Ren et al. (2003) has suggested that a close to $94 \%$ of the variability in water quality classifications is explained by industrial land area in Shanghai which is the biggest city in the Yangtze River watershed. This study site, Hanyang District is a part of the Jianghan Plain, which is a historically famous and ecologically important wetland (Fang et al. 2005) in central China. However, only few studies have documented the interrelationship of urban land use and lake water quality in this area.

\subsection{Description of the Watersheds}

The study area contains four watersheds: Lake Long Yang (LY, 1,073.60 ha), Mo Shui (MS, 1,924.83 ha), Nan TaiZi (NTZ, 2503.68 ha), and San Jiao (SJ, 1,123.56 ha), as a portion of Hanyang District $\left(2.21 \times 10^{4}\right.$ ha), Hubei Province, China (E $114^{\circ} 3^{\prime} \sim 114^{\circ} 17^{\prime}$, N $30^{\circ} 25^{\prime} \sim 30^{\circ} 36^{\prime}$ ) (Fig. 2). Precipitation occurs mostly in spring and summer, especially in April to July. As a typical urban-rural area in the central of China, Hanyang has experienced significant urbanization expansion (population from 344,800 in 1989 to 536,749 in 2007) and consequently has had

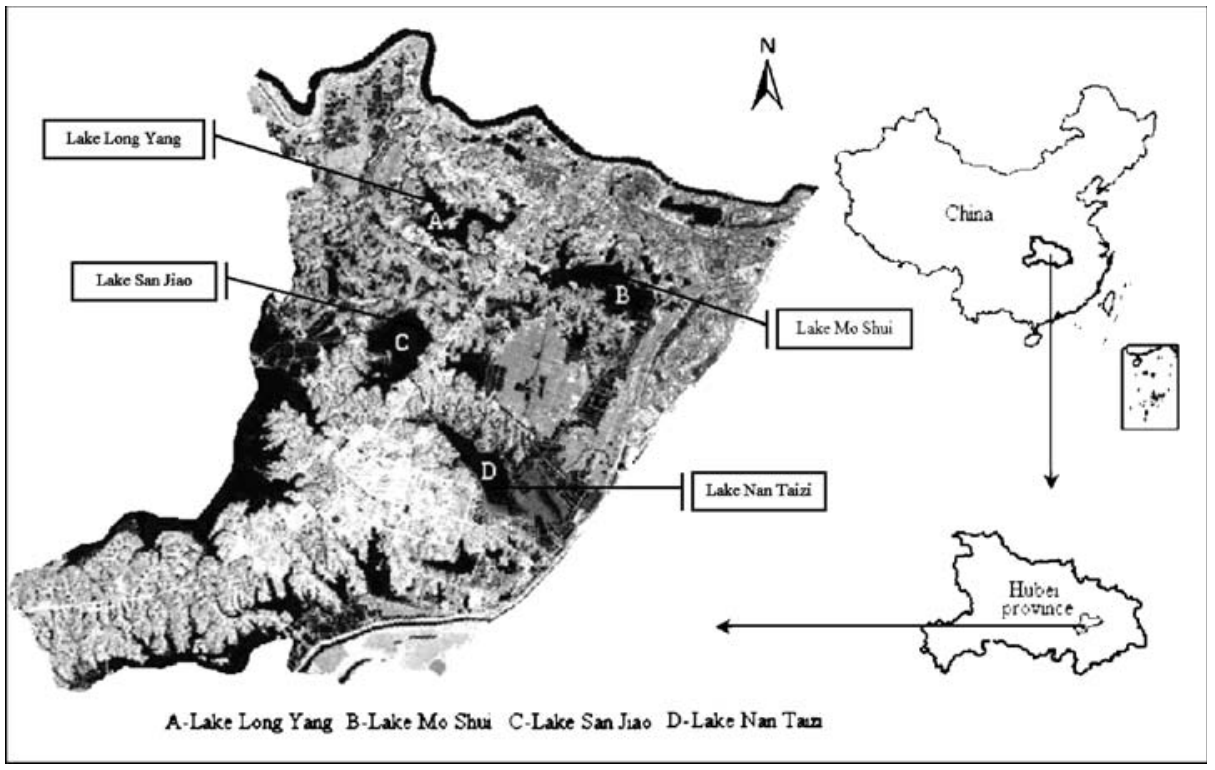

Fig. 2 Location of study sites. Hanyang District is located on the west of Yangtze River and the south of Han River 
dramatic changes in urban spatial structure and residential density during the past two decades (population density from 3,768 people $/ \mathrm{km}^{2}$ in 1989 to 4,951 people $/ \mathrm{km}^{2}$ in 2007). In response to these changes, the four lakes have been providing wastewater sinks for the urban surface runoff and household wastewater. Currently, the Nan TaiZi wastewater treatment plant (WWTP) is functional and Zhuankou WWTP will be built in the near future. Under the current situation, the separation of the storm and sanitary sewer systems to prevent combined sewer overflows is weak, and the non-point sources are unregulated in the Hanyang District.

\subsection{Catchments and Water Quality}

Four lakes were divided into several catchments using the Soil \& Water Assessment Tool (SWAT, Grassland, Soil \& Water Research Laboratory 2001) model based on the 1:10,000 DEM data from National Fundamental Geographic Information System of China. Seventeen catchments were generated from watersheds: four catchments in Lake Long Yang, six in Lake Mo Shui, four in Lake Nan TaiZi, and three in Lake San Jiao (Fig. 3). Seventy sampling sites were chosen in which 15, 21, 20 and 14 sites from Lake Long Yang, Mo Shui, Nan TaiZi and San Jiao, respectively. These samples

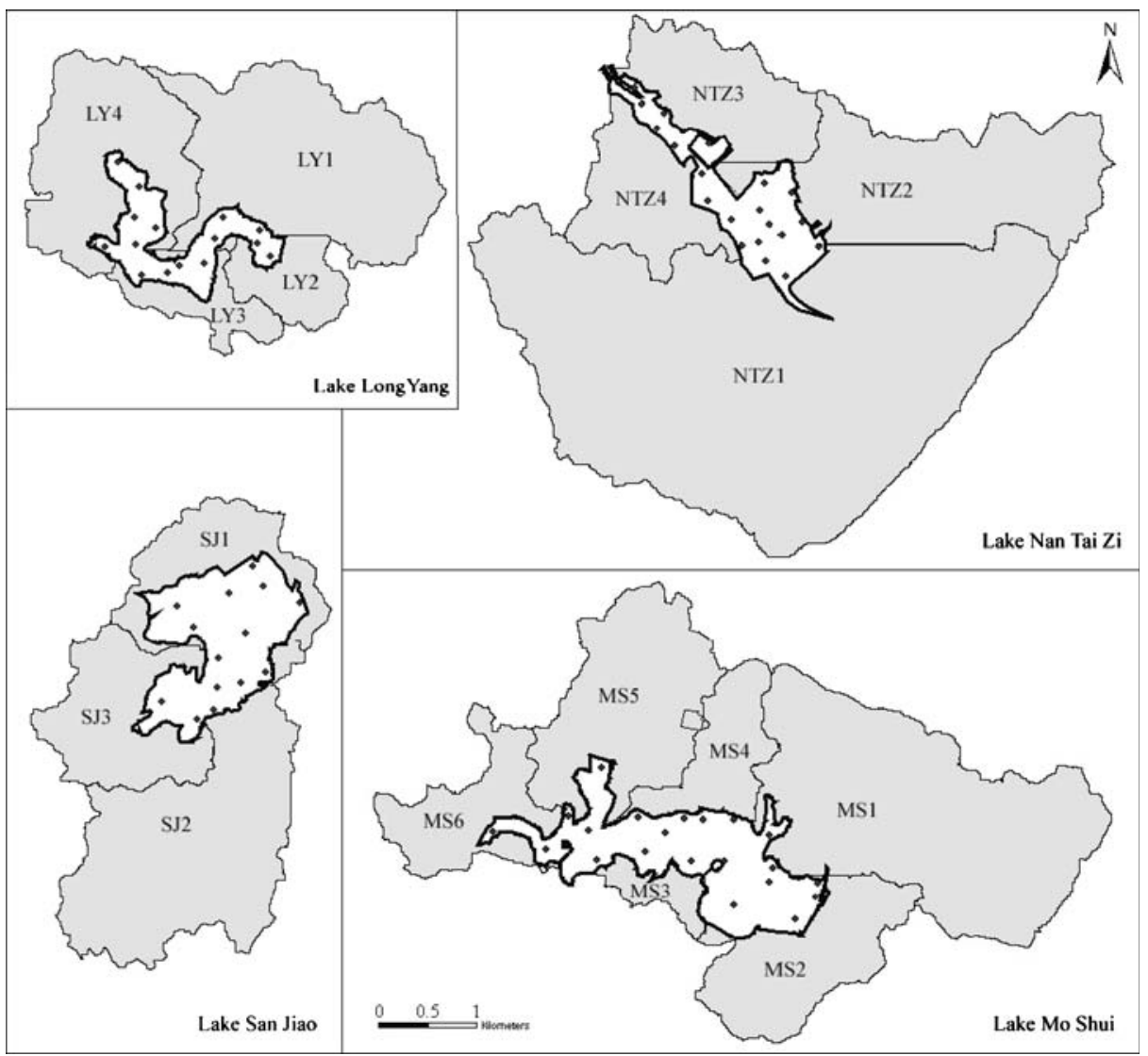

Fig. 3 Distribution of sampling sites in different catchments. Black points denote the sample sites 
were assigned within the lakes to a particular portion of the watersheds to ensure that not less than three sampling are taken to represent the effects of land use from catchments. We assume that the sampling points are relatively independent or less affected by each other.

Sampling data were typically collected in $24 \sim 48 \mathrm{~h}$ after rainstorms in July 2004. Based on the national environmental quality standard for surface water (GB38382002) by State Environmental Protection Administration of China (2002), the water quality parameters in this study were selected as total nitrogen (TN), total phosphorus (TP), ammonium ( $\left.\mathrm{NH}_{4}\right)$, chemical oxygen demand (COD), and non-metallic element, Selenium (Se). We obtained the data of $\mathrm{NH}_{4}$ and COD in each sample site using potable water quality analyzers, 6600EDS (YSI Int.) and U-10 (Horiba Int.). In the process of field investigation, three replicates were averaged in each sample site. The alkaline potassium persulfate digestion-UV spectrophotometric method was applied to determine the measurements of TN. The ammonium molybdate spectrophotometric method was used to measure TP. The non-metallic Se data were obtained by plasma transmit spectrum instrument ICP-OES (VISTA-MPSX).

\subsection{Land Use Classification}

Land use data were extracted through the high-resolution Quickbird multispectral imagery (resolution of $0.6 \mathrm{~m}$ ) acquired on January 23, 2003 (SPOT Company). The supplementary data for study were 1:50000 Relief Maps supported by National Geomatics Center of China. Auto-interpretation by computer from Quickbird imagery could meet with the disturbance of shadows in the high-resolution $(0.6 \mathrm{~m})$ imagery. Therefore visual interpretation method was employed in the land use classification of the high-resolution image in ArcGIS 8.1 (ESRI 2001). The satellite-derived land use data estimated from 2003 Quickbird image were calibrated by fieldwork ( 79 samples) to achieve a better accuracy $(85 \%)$.

According to the Standard of Land use Classification of China (Table 1), the modified classification system employed fifteen general categories: canal, pond, agriculture (AG), forest, artificial grassland (Grass), rural habitation ( $\mathrm{RH})$, urban habitation (UH), industry, commercial, impervious road (IR), pervious road (PR), school, office and open space (Office), land leveled (LL), and bottomland (BL). We generated buffer zones through drawing a line from the edge of the lake to the furthest edge of the watershed, and then dividing that line into equal segments, with each $10 \%$ of the total distance associated with the edge of a circle around the lake by using the buffer tools in ArcGIS 8.1 (ESRI 2001). One hundred percent of a buffer zone is equal to the whole catchment. The proportion of land use type was extracted for catchments and the proportions of land use types were calculated in buffer zones.

Landscape indices were used to quantify the spatial characteristics for the buffers (McGarigal and Marks 1995). Here we used Shannon's Diversity Index (SHDI), Shannon's Evenness Index (SHEI), and Landscape Division Index (DIVISION) measured through FRAGSTATS3.3, an open software to determine the spatial pattern of land use. SHDI was applied to measure the land use diversity. SHDI should increase as the number of different land use types increases and the proportional distribution of area among land uses becomes more equitable. SHEI is expressed as an even distribution of area among land uses. SHEI approaches ' 1 ' when the distribution of area becomes increasingly even. DIVISION is interpreted as the 


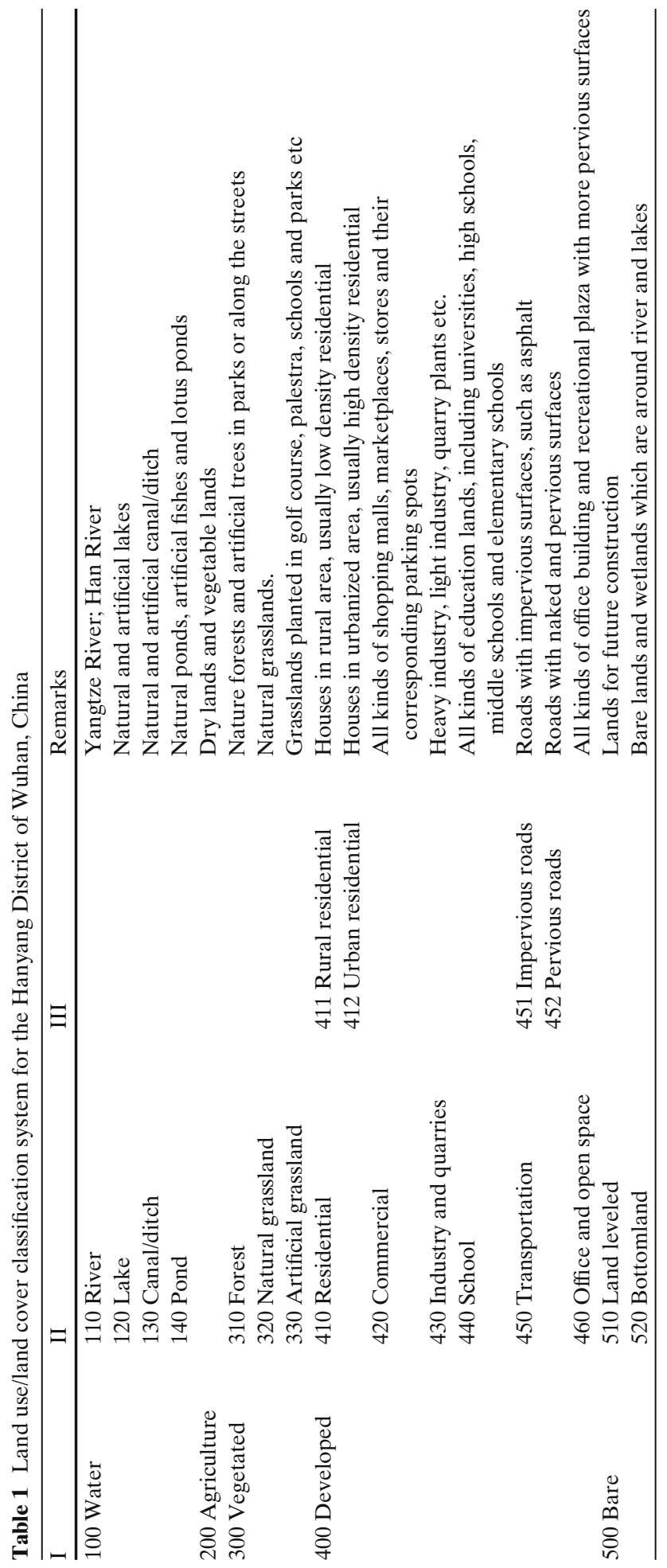


probability of land use area distribution. DIVISION achieves its maximum value (1.0) when the landscape is maximally subdivided.

\subsection{Modeling the Relationship Between Land Use and Water Quality}

The delivery process of pollutants from upstream contributing areas to a receiving downstream point is a multiple, often episodic process (Phillips 1989). Factors, such as land use types, soil, slope and geology, are important factors impacting the NPS pollutants transport. NPS pollutants delivered from NPS sources such as residential, urban, and agriculture areas are absorbed, deposited and re-separated out when flowing through land use types, especially through forest and grassland adjacent to water bodies.

In this study, we used the stepwise regression model to evaluate NPS pollutants attenuation in flow through various land uses to the lakes (Basnyat et al. 1999, 2000). In this model, proportions of fifteen land use types were chosen as land use variables. The pollutant concentrations of TN, TP, $\mathrm{NH}_{4}, \mathrm{COD}$, and Se were put into the model as dependent variables to identify the land use variables effectively impacting on water quality. Thus the NPS pollutant concentration $\left(N P S_{i}\right)$ can be expressed in the following equation:

$$
N P S_{i}=\alpha \times \exp \left(\beta_{1} \mathrm{Canal}_{i}+\beta_{2} \text { Pond }+\beta_{3} \mathrm{AG}+\ldots \ldots \beta_{14} \mathrm{LL}+\beta_{15} \mathrm{BL}_{i}\right)
$$

Equation 1 can also be expressed as

$$
\operatorname{Ln}(N P S i)=\chi+\beta_{1} \text { Canal }_{i}+\beta_{2} \text { Pond }+\beta_{3} \mathrm{AGi}+\ldots \ldots \beta_{14} \mathrm{LL}+\beta_{15} \mathrm{BL}_{i}
$$

Where $\alpha$ and $\chi$ are constants, and $\beta_{1}, \ldots \beta_{15}$ are coefficients that depict the direction and strength of the relationships between proportion of land use type and $N P S_{i}$. When $\beta$ value is positive, it indicates that this particular land use type is exporting $N P S_{i}$. When $\beta$ value is negative, this particular land use type is reserving $N P S_{i}$. The model allows us to find out the effect of land use to $N P S_{i}$ within different buffers. The analyses process was carried out by linear regression in SPSS 10.0 for windows, the method chosen was stepwise, and $F$ test was used to the stepping method criteria, more specific, the probability of $F$ to enter was $\leq 0.100$, the probability of $F$ to remove was $\geq 0.110$. $T$ test was used to identify the significant of the coefficients of independent variables $(p \leq 0.05)$ entered in the final stepwise model.

\section{Results}

\subsection{Water Quality}

The concentrations of five surface water quality parameters in seventeen catchments were monitored (Fig. 4). The levels of TN, TP, COD and Se were over the national grade V (seen in GB3838-2002 by EPA of China 2002). Specifically, the concentration of Se was ten times greater than that of the grade V. Surface water loads were higher in Lake Long Yang, but lower in Lake San Jiao (grade II). The variability of these parameters in the catchments was remarkable. For example, catchments LY1 and LY2 had the highest concentration values comparing with other catchments for $\mathrm{TN}, \mathrm{TP}, \mathrm{NH}_{4}$, and COD. Reversely, these four parameters in catchments SJ1, SJ2, SJ3, NTZ3, and NTZ4 were lower. 

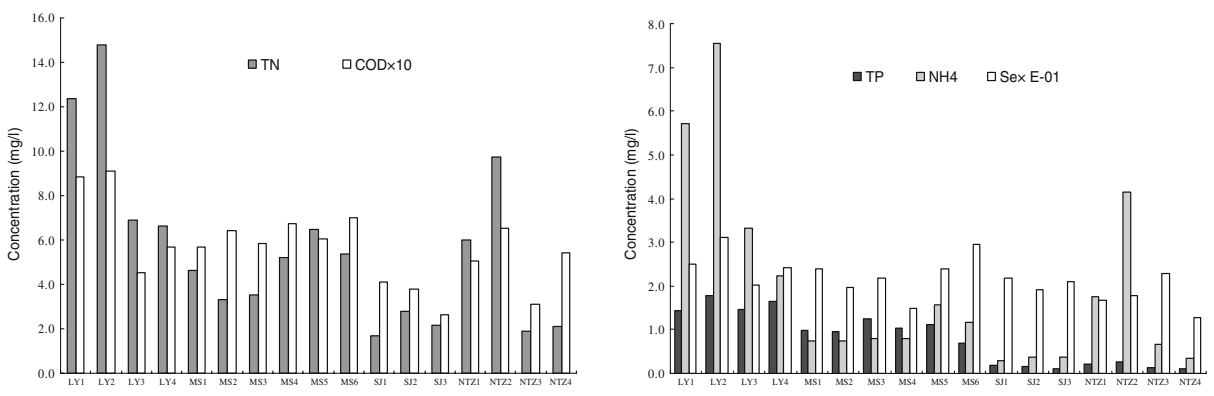

Fig. 4 Changes in surface water quality of TN, TP, $\mathrm{COD}, \mathrm{NH}_{4}$ and $\mathrm{Se}$ in 17 catchments, in which the concentration data of COD were smaller ten times than the monitoring data, and the concentration data of Se were bigger ten times than the monitoring data

\subsection{Land Use Characteristics}

Fifteen land use types were classified in the study. Proportions of land uses in the $10 \% \sim 100 \%$ buffer zones along the lakeshores were generated; only the results of land use classification in $10 \%, 50 \%$ and $100 \%$ buffer zones were listed due to the size of the datasets (Fig. 5).
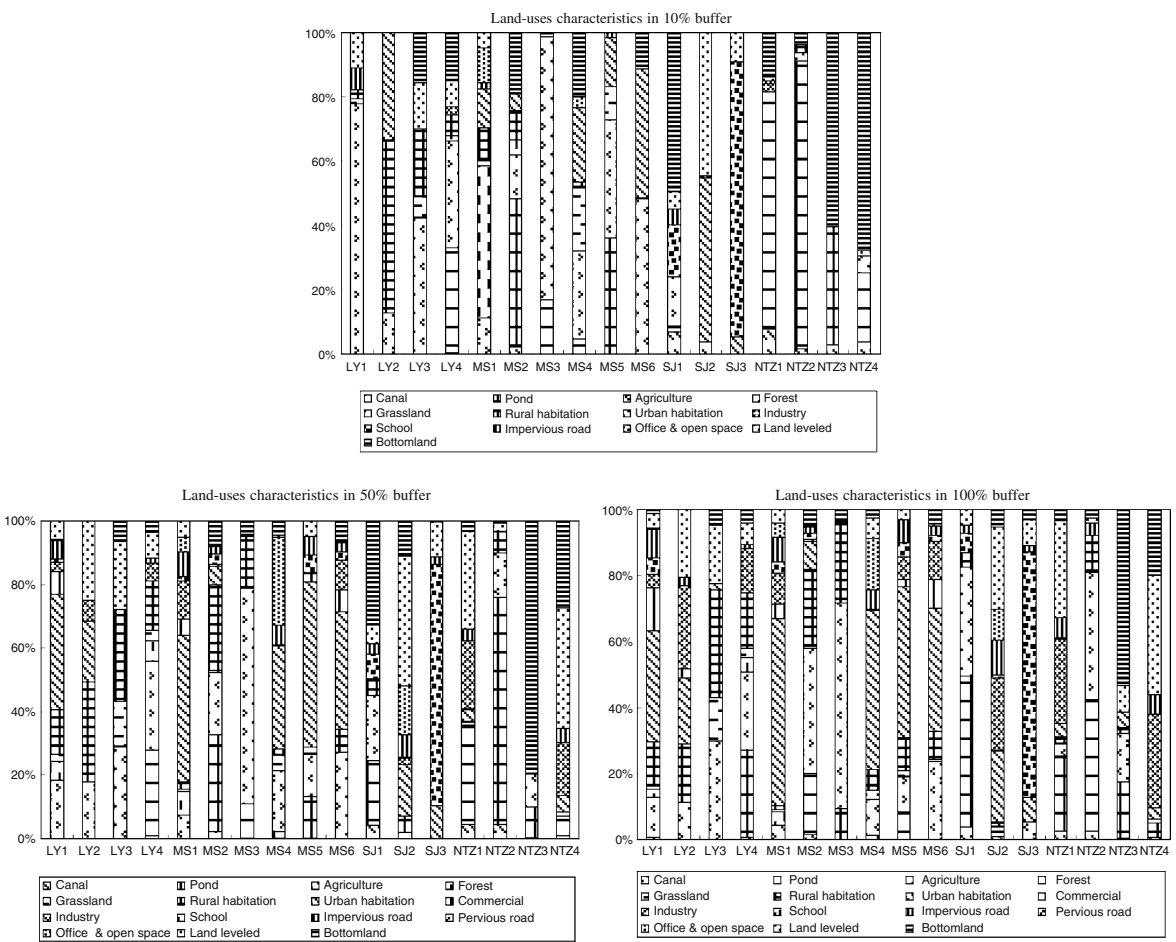

Fig. 5 Land use proportions in 10\%, 50\% and 100\% buffers in 17 catchments. Land use proportions varied with the size of the buffer zones in 17 catchments 
Land use proportions varied with the increasing of buffer zone size. The main land use type, agriculture exhibited four clear trends of proportional changes. Firstly, its proportion increased gradually with the distance to the lakeshore in catchments MS2, SJ1, and NTZ2. The area proportion increased from $2.52 \%$ in $10 \%$ buffer to $38.68 \%$ in $100 \%$ buffer in NTZ2. Secondly, the agriculture proportion decreased gradually in catchments LY1, LY2, LY4, MS1, MS3, MS6, and NTZ4. For example, the proportion increased from $77.83 \%$ in $10 \%$ buffer to $12.31 \%$ in $100 \%$ buffer in LY1. Thirdly, the proportion trend was unimodal in LY2, in particular, the peak proportion of agriculture was at $17.91 \%$ in $50 \%$ buffer. Finally, the agriculture land type was absent in some buffer zones especially near the lakeshore in catchments SJ1, SJ2, and NTZ1. There was no agriculture land type in the $40 \%$ buffer in SJ2. Other land uses had similar dynamic trends as well as agriculture land use (Fig. 5).

The spatial pattern of land uses varied in the buffer zones. The large proportion of every land use could provide a clue for land use distribution. The fluctuating values of the landscape indices with buffer distance from the lakeshore depicted the changing patterns of land use (Fig. 6). With the buffer size increasing, the values of SHDI increased gradually in LY2. Similar situations also occurred in catchments LY4, MS5, MS6, SJ2, SJ3, NTZ1, NTZ2, NTZ3, and NTZ4. A "U” shaping curve, a unimodal trend and a fluctuating pattern were also symbols of the SHDI in other catchments. The second landscape index, SHEI displayed both increasing trend and decreasing trend, "U" shaping curve, unimodal trend and fluctuating pattern with the increasing of the buffer size. The third landscape index, DIVISION also showed
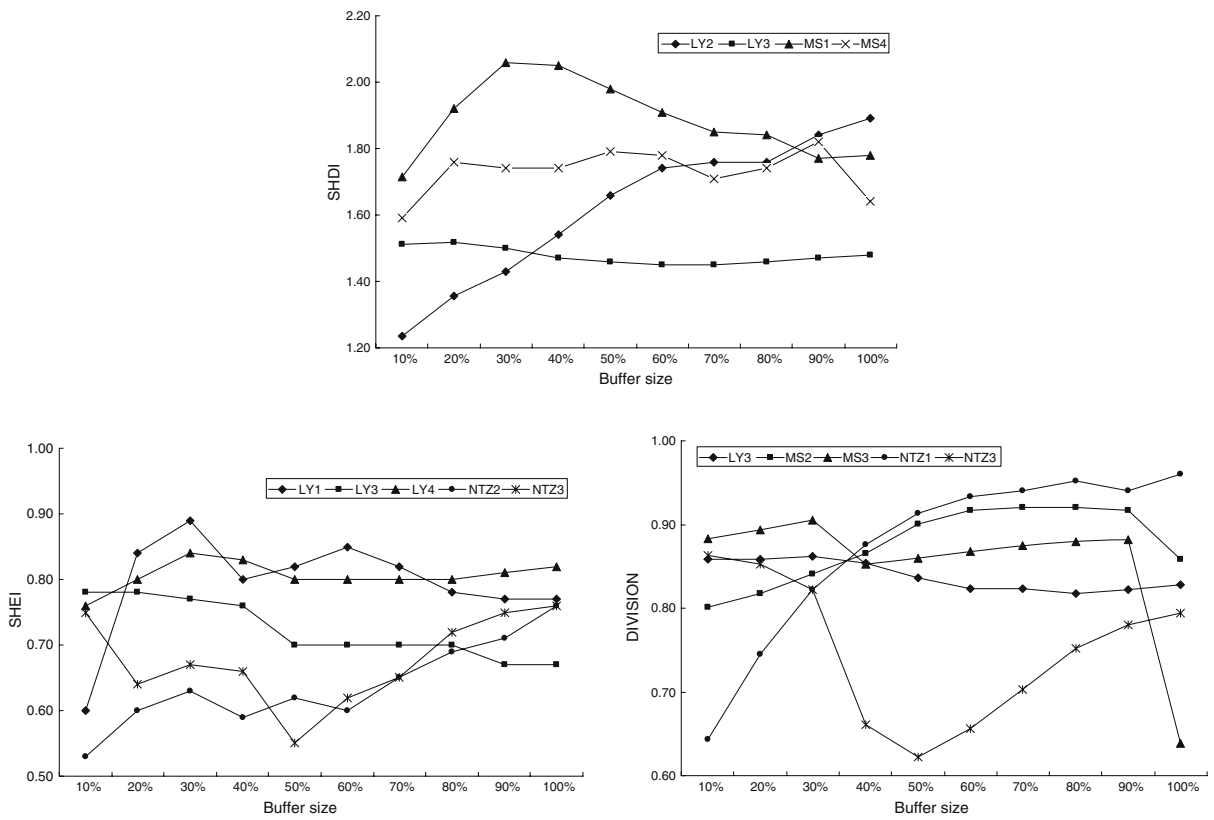

Fig. 6 Typical trends of landscape indices with buffers size increasing in 17 catchments. Four types of typical trends of SHDI, i.e. increasing trend, "U" shaping curve and unimodal trend and fluctuating pattern with buffer size increasing. And five types of typical trends of SHEI and DIVISION, i.e. increasing trend, decreasing trend, "U" shaping curve, unimodal trend and fluctuating pattern with the increasing of buffer size 


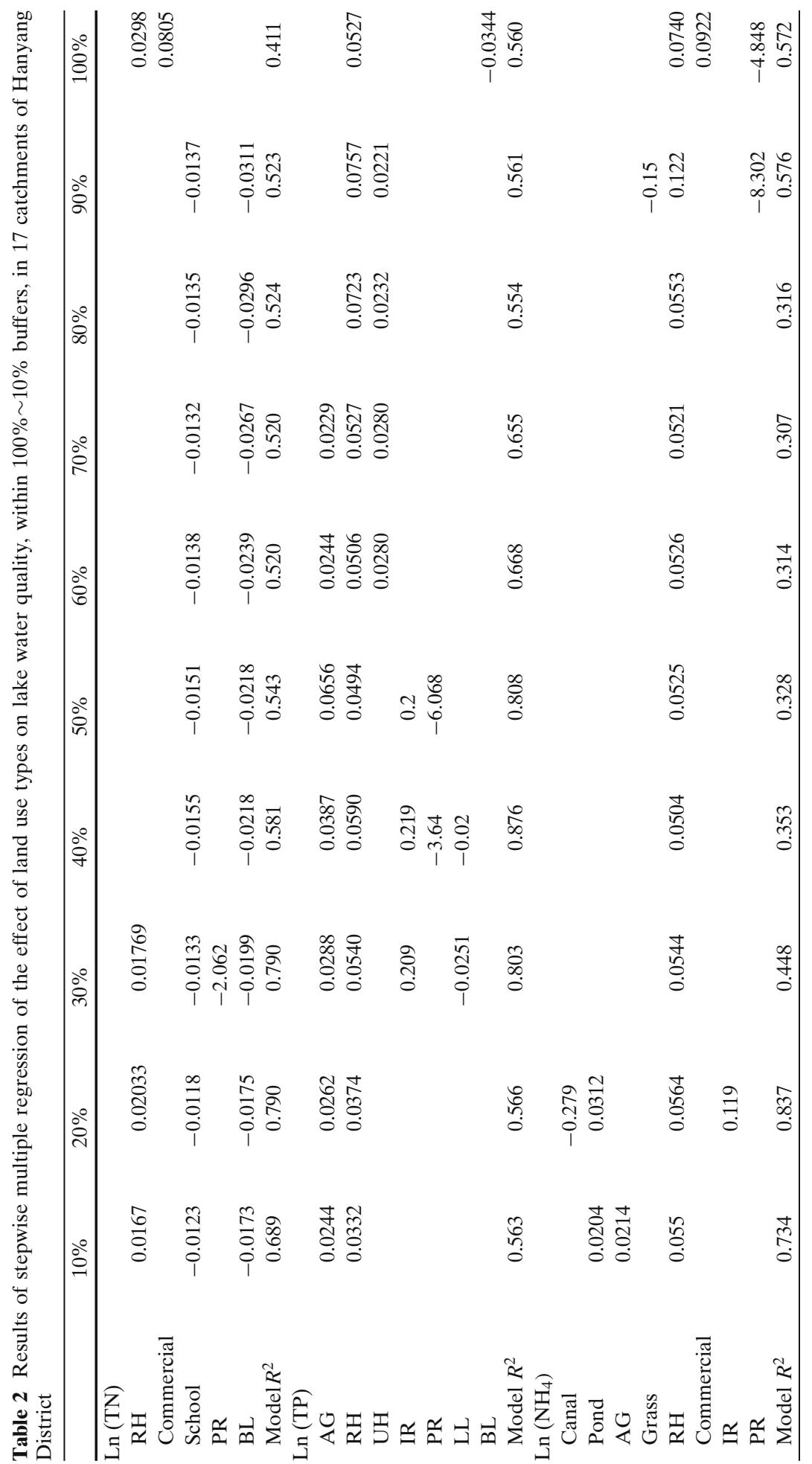




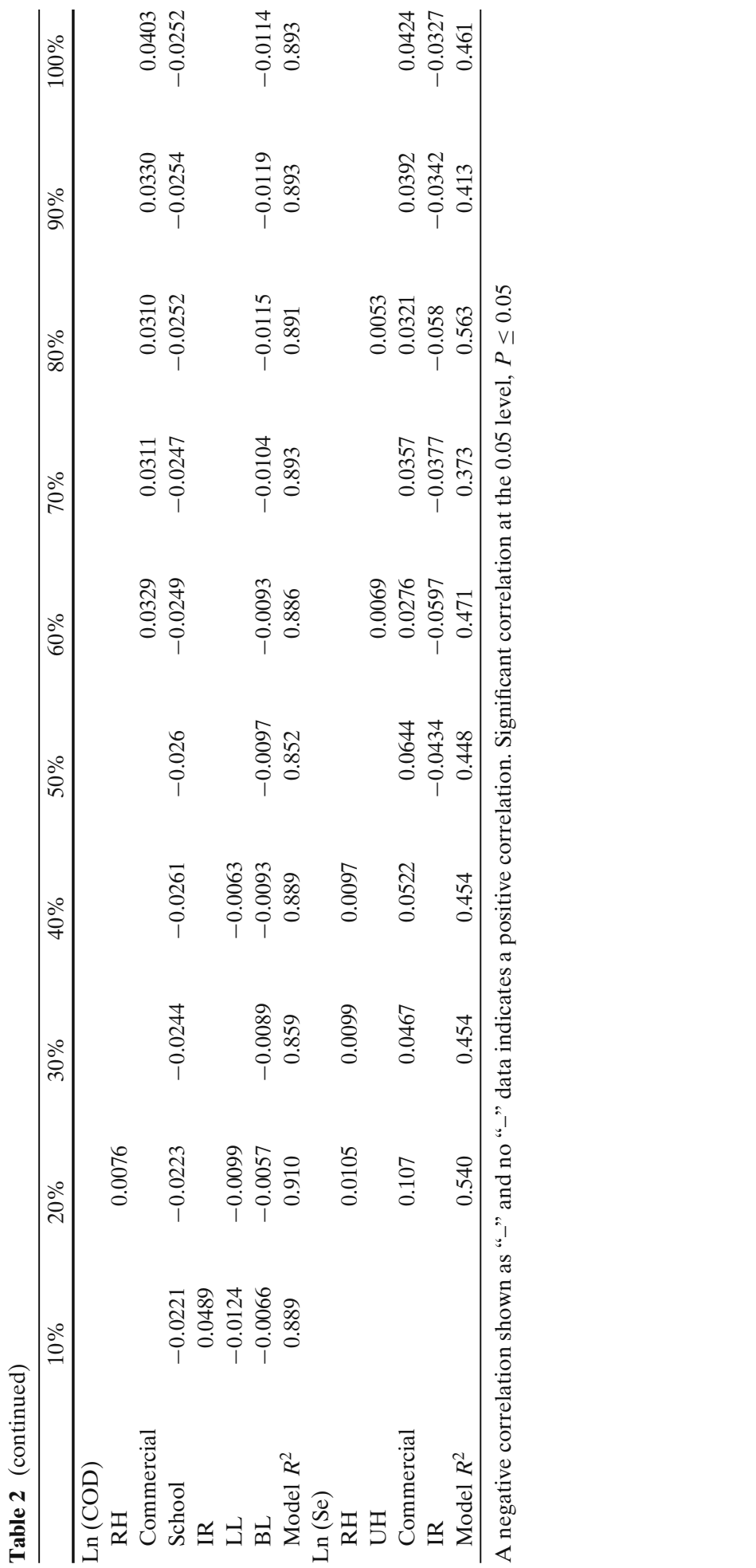


similar fluctuating trends with SHEI in the seventeen catchments at various buffer levels.

\subsection{Relationship Between Land Use and Water Quality}

The relationships between land use proportion and water quality at watershed scale ( $100 \%$ buffer) were presented in Table 2 . The results indicated that proportions of rural habitation and commercial land use had a positive correlation with TN concentration $\left(R^{2}=0.411, P=0.025\right)$ within $100 \%$ buffer. TP concentration had a positive relationship with proportion of rural habitation, and a negative relationship with proportion of bottomland $\left(R^{2}=0.560, P<0.001\right)$. Proportion of rural habitation, commercial land use, and pervious road contributed to a significant relationship with $\mathrm{NH}_{4}$ concentration $\left(R^{2}=0.572, P=0.01\right)$. COD concentration was positively correlated to proportions of commercial land use and school, and negatively to proportion of bottomland $\left(R^{2}=0.893, P<0.001\right)$. Proportion of commercial land use had a positive effect on Se concentration, while impervious road had a negative effect on $\operatorname{Se}\left(R^{2}=0.461, P=0.013\right)$.

Table 3 Correlation between water quality and landscape indices
*Correlation is significant at the 0.05 level, $P \leq 0.05$; **correlation is significant at the 0.01 level, $P \leq 0.01$

\begin{tabular}{|c|c|c|c|c|c|c|}
\hline & & $\mathrm{TN}$ & $\mathrm{TP}$ & $\mathrm{NH}_{4}$ & COD & $\mathrm{Se}$ \\
\hline \multirow[t]{3}{*}{$10 \%$ buffer } & DIVISION & & $0.633^{* *}$ & & & \\
\hline & SHDI & & $0.490 *$ & & & \\
\hline & SHEI & & $0.580 *$ & & & \\
\hline \multirow[t]{3}{*}{$20 \%$ buffer } & DIVISION & & $0.548^{*}$ & & & \\
\hline & SHDI & & & & & \\
\hline & SHEI & & $0.603 *$ & & $0.487 *$ & \\
\hline \multirow[t]{3}{*}{$30 \%$ buffer } & DIVISION & & $0.496^{*}$ & & & \\
\hline & SHDI & & & & & \\
\hline & SHEI & $0.509 *$ & $0.556^{*}$ & & $0.598 *$ & \\
\hline \multirow[t]{3}{*}{$40 \%$ buffer } & DIVISION & & $0.527^{*}$ & & $0.538 *$ & \\
\hline & SHDI & & & & & \\
\hline & SHEI & & $0.503^{*}$ & & & \\
\hline \multirow[t]{3}{*}{$50 \%$ buffer } & DIVISION & & $0.494 *$ & & $0.588^{*}$ & \\
\hline & SHDI & & & & $0.510 *$ & \\
\hline & SHEI & & $0.486^{*}$ & & $0.642 * *$ & \\
\hline \multirow[t]{3}{*}{$60 \%$ buffer } & DIVISION & & & & $0.591 *$ & \\
\hline & SHDI & & & & $0.530 *$ & \\
\hline & SHEI & $0.501 *$ & $0.502 *$ & $0.485^{*}$ & $0.655^{* *}$ & \\
\hline \multirow[t]{3}{*}{$70 \%$ buffer } & DIVISION & & & & $0.580 *$ & \\
\hline & SHDI & & & & $0.527^{*}$ & \\
\hline & SHEI & $0.557^{*}$ & $0.494 *$ & $0.548^{*}$ & $0.665^{*}$ & \\
\hline \multirow[t]{3}{*}{$80 \%$ buffer } & DIVISION & & & & $0.565^{*}$ & \\
\hline & SHDI & & & & $0.504 *$ & \\
\hline & SHEI & $0.554 *$ & & $0.562 *$ & $0.599 *$ & \\
\hline \multirow[t]{3}{*}{$90 \%$ buffer } & DIVISION & & & & $0.574 *$ & \\
\hline & SHDI & & & & $0.530 *$ & \\
\hline & SHEI & & & & $0.541 *$ & \\
\hline \multirow[t]{3}{*}{$100 \%$ buffer } & DIVISION & & & & & \\
\hline & SHDI & & & & & \\
\hline & SHEI & $0.518^{*}$ & & $0.523^{*}$ & & \\
\hline
\end{tabular}


Land use types related to water quality changed with the increasing sizes of buffer zones (Table 2). Proportion of school and bottomland had significant relationship with TN concentration $\left(R^{2}=0.523, P=0.006\right)$ in the $90 \%$ buffer, which was different with land use types in the $100 \%$ buffer. Within $40 \%$ $90 \%$ buffers, the land use types related to TN were concurrent with the $100 \%$ buffer. However, rural habitation, school, pervious road, and bottomland all had significant relationship with $\mathrm{TN}$ in the $30 \%$ buffer, and then the land use types related significantly to TN only involved rural habitation, bottomland, and school in the $10 \% \sim 20 \%$ buffer. Bottomland had negative relationship with TP in the $100 \%$ buffer, whereas bottomland was insignificant with TP in the 10\% 90\% buffers. Land use types were coincident within $80 \% \sim 90 \%$ buffers, similar within $60 \% \sim 70 \%$ buffers, and different in $50 \%$ buffer. Land leveled had negative effect on TP in the $40 \%$ buffer. Only rural habitation and agriculture had effects on TP in the $10 \% \sim 20 \%$ buffers. The way that various types of land uses are related to $\mathrm{NH}_{4}, \mathrm{COD}$, and Se also changed with buffer sizes.

Water quality was also strongly related to the spatial pattern of land use. As shown in Table 3, DIVISION had a significantly positive relationship with TP concentration in the $10 \% \sim 50 \%$ buffers and with COD concentration in $40 \% \sim 90 \%$ buffers. SHDI had a positive effect on TP concentration in the $10 \%$ buffer and on COD concentration in the $50 \% \sim 90 \%$ buffers. However, an insignificant relationship between SHDI and water quality was represented in $20 \%$ 40\% and $100 \%$ buffers. To the relationship of SHEI with water quality, our results indicated a positive relationship with $\mathrm{TN}$ and $\mathrm{NH}_{4}$ in the $100 \%$ buffer, with COD in the $90 \%$ buffer, and with $\mathrm{TN}, \mathrm{NH}_{4}$ and COD in the $80 \%$ buffer. SHEI was also significantly related to $\mathrm{TN}, \mathrm{TP}, \mathrm{NH}_{4}$, and COD in the $60 \%$ to $70 \%$ buffers.

\section{Discussion}

\subsection{Impact of Land Use on Water Quality}

Previous studies have suggested the general trend of the impact of urban land use on water quality. For example, the total suspended solids (TSS), TP, and TN concentrations from intensive agriculture and urban areas are normally 10 100 times greater than those from the forested and idle lands in the Great Lakes region (Sonzogni 1980). Constructed sites, including commercial, industrial, high density residential, and street, are main pollutant sources in all urban land use types (Bannerman et al. 1993; Tong and Chen 2002). Our results on the correlation between water quality and land use at watershed scale (Table 2) also showed that the proportions of rural habitation and commercial land use had positive correlations to TN, TP, $\mathrm{NH}_{4}$, COD, and Se concentrations; proportion of bottomland had negative impact on TP and COD concentrations; proportion of pervious road and school yielded negative influence on $\mathrm{NH}_{4}$ and COD concentrations, respectively. Our results also indicated that proportion of impervious road appeared to have a negative effect on the nonmetallic Se concentration. This could be due to the combination of storm and sanitary sewer systems, in particular, the negative influence of the impervious road on Se may reflect the negative relationship between sewer systems and Se. The non-metallic element could be reduced by the sediment basins and WWTPs available in the area. 
Our study suggests that the correlation between water quality and land uses was due to the land use patterns in the buffers. For example, rural habitation positively contributed to $\mathrm{TN}$ in the $30 \% \sim 10 \%$ buffers, but this phenomenon did not occur in the $90 \% \sim 40 \%$ buffers. TN was negatively correlated to school and bottomland, and the correlation was significant in $90 \% \sim 10 \%$ buffers. Pervious road only influenced $\mathrm{TN}$ in the $30 \%$ buffer. There were differences in the influence of land use types on TP. For example, TP was affected by rural habitation in all buffers, by agricultural in the $70 \% \sim 10 \%$ buffers, and by impervious road in the $50 \% \sim 30 \%$ buffers. Other land uses, such as pervious road and bottomland had negative correlations with TP.

It was specially noted that the impervious road had a negative relationship with selenium (Se) in the 10\% 40\% buffers. Commercial land use, rural habitation and urban habitation could provide sources for Se. The positive relationship between Se and commercial land use was analyzed along the gradient of buffers from $10 \%$ to $100 \%$. The influence of rural habitation appeared in the buffers adjacent to lakes (10\% 30\% buffers). The influence of urban habitation was significant in $60 \%$ and $80 \%$ buffers on selenium. It should not be overlooked that the relationship of land use types and Se was insignificant in the $10 \%$ buffer.

The characteristics of land use in this research suggested that agriculture, bottomland, and pond distributing around the lakes formed a "concentric circle" structure. Lake was placed in the center of the structure as the first inner circle. Agriculture, bottomland, pond, rural habitation, and land leveled around the center composed the second inner circle. It was apparent that the second inner circle functionally affected the water quality within $50 \%$ buffer. Industry, urban habitation, and commercial formed the outer circle which could influence water quality in the $60 \%$ buffer and beyond.

The results above were based not only on the area proportion of land uses but also on the spatial pattern of land uses. As shown in Table 3, the correlation of landscape indices and water quality changed in different buffers. The SHEI, representing even distribution of land use area, had a significantly positive correlation with water quality especially in the $60 \sim 70 \%$ buffers. Clearly, the distribution pattern of land use was a critical factor affecting water quality and the even distribution of land use contributed to water pollution. The information on land use proportion exhibited the impact of land use on water quality in a two dimensional way; however it overlooked the effects of the distribution patterns of land uses. Spatial analysis addressed the deficiency of the two-dimension way with incorporating of the spatial distribution patterns of land uses.

We agree with the study of O'Neill et al. (1997) in which the spatial pattern of land use played an important role in modulating land use effects on water quality. We could literally see the "concentric circle" structure sprawling from the lakeshores to the watershed boundaries. The intermixing of land use, the landscape's poor connectivity, and the changing property of land use types contributed to the relationship of land use types with water quality within different buffers. For land use change, this could have significant impacts on runoff volume and consequently pollution concentrations (Tang et al. 2005; Van Dessel et al. 2008; Cao et al. 2009).

More realistically, the impact of land use on water quality could form a dynamic complex in a certain spatial region due to its diversity in area proportion and spatial pattern of land use. So the impact of land use on water quality happens to change along the expansion of buffers. We further explain that there is not enough land use 
area significantly related to water quality when the study area is under the effective buffer zone, so that the relationship between the land use and water quality appears weak. On the other hand, when beyond the effective buffer zone, other land use types intercepting into the relationship of land use with water quality can reduce the impact of land use on water quality. Our study results support the proposed dynamic complex hypothesis (Fig. 1). For instance, rural habitation had significant impact on TN in the 10\% 30\% buffers; and then the impact diminished in the $40 \% \sim 90 \%$ buffers; surprisingly, it occurred at the entire watershed scale.

\subsection{Evaluation of Correlation Between Land use and Water Quality}

The next question is how to evaluate the dynamic and complex relationship between land use and water quality as discussed above. We used correlation coefficient $\left(R^{2}\right)$ in the stepwise regression model as explanatory variable (Sliva and Williams 2001) to address the issue. Using $R^{2}$ to compare the relationships at catchments scale $v s$. buffers scale allowed us to determine whether land use near water body is a better predictor of water quality than that over the entire catchments (Hunsaker and Levine 1995; Johnson et al. 1997; Sliva and Williams 2001; Sawyer et al. 2004).

The curve of the correlation coefficient $\left(R^{2}\right)$ could help clearly indicate the character of relationship between land use and water quality at various spatial scales (Fig. 7). $R^{2}$ of TN was lower at catchments scale $\left(R^{2}=0.411\right)$ than that in other buffers; $R^{2}$ of TP at catchments was similar to $R^{2}$ in $10 \%, 20 \%, 80 \%$, and $90 \%$ buffers. The peak values of the TN and TP curves revealed that land use had strongest influence on TN and TP in 20\% 30\% and 30\% 50\% buffers, respectively. Elsewhere, before or after the peak range, the influence all was weaker. This also supported the proposed dynamic complex hypothesis (Fig. 1). There were two peaks associated with the $R^{2}$ curves of $\mathrm{Se}$ and $\mathrm{NH}_{4}$, suggesting that there were two regions where the land use significantly affected the concentrations of $\mathrm{Se}$ and $\mathrm{NH}_{4}$. The fluctuating $R^{2}$ curve of COD might indicate similar effects of land use on COD within all buffers.

We found an irregular fluctuation in the curve of $R^{2}$ within TN, TP, $\mathrm{NH}_{4}, \mathrm{COD}$, and Se concentration gradient. Although the interactions among water pollutants were suggested (Shao et al. 2006), the water pollutants were independent with each

Fig. $7 R^{2}$ curves appearing in multiple regression model from $10 \%$ to $100 \%$ buffers

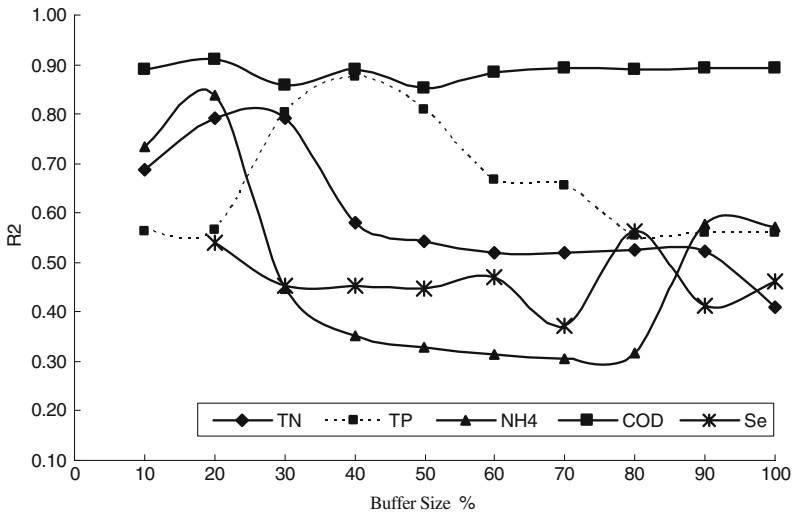


other to some degree. Another reason was that these explanatory variables in the regression model referred to the proportion of land use, not to the pollutants concentration. Previous research and this study all assumed that same land use type holds same pollutant loads. In fact, anthropogenic influences could result in different pollutant concentrations on same type of land use. Therefore, it is essential to study the relationship between anthropogenic influences and water quality to a further step.

The change of land use proportion and landscape pattern along the gradient of buffer demonstrates the strong linkage between pattern and process. As suggested by Wiens (2002), the relationships of terrestrial landscape with freshwater ecosystems that are apparent at one scale may disappear or be replaced by other relationships at other scales. Furthermore, the pattern-process relationships might be a threshold phenomenon where only changes in pattern near the threshold occurs (Gustafson 1998). Clearly, our proposed dynamic complex hypothesis agrees very well with the general principle of landscape ecology. Most importantly, our study results explain why there are conflicting results on the impact of land use on water quality in buffer versus in catchments in the literatures. Furthermore, spatial pattern is the determinant factor for water quality and even for aquatic ecosystems (Alberti et al. 2007), and land use regulation should be put into critical step for urban planning.

\subsection{Application in Nonpoint Source Pollution Management}

Water quality of Lake Long Yang, Mo Shui, Nan Taizi, and San Jiao has all been degraded, because these lakes have received discharges of residential wastewater, industry wastewater, and multiple wastewater treatment plant effluent, combined with urban storm runoff through sewer system. WWTP alone may not significantly affect the water quality while the combined effects from point source and non-point source (urban land) can be reflected in the water quality data (Wang 2001). The results from this study can be a useful support for improving water quality of the four lakes. This study displayed that there were different effective buffer zones to lake water pollutants from urban NPS pollution. Expect for $\mathrm{TN}, \mathrm{NH}_{4}$ and COD, which buffer sizes were the same buffer size $20 \%$, the effective buffer size to TN was in $40 \%$; and the effective buffer size to Se was in $80 \%$. The $R^{2}$ of the effective buffer zone was higher than that of watershed scale. The effective buffer zone of pollutants could provide new information and ideas for planning and management.

There is an increasing need to design and implement best management practices (BMPs) that will effectively improve water quality. Riparian buffers, constructed wetlands, porous pavement, infiltration basins, infiltration trenches, and other practices can intercept surface water runoff, treat tile drainage. In Berlin, BMPs converting existing retention tanks to soil filter tanks could offer a high effectiveness concerning stormwater treatment at relatively low costs (Sieker and Klein 1998). However, these practices are not equally effective in all locations. How to optimize the placement of these practices at a watershed scale is the key to optimize their effectiveness. Tomer (2002) has already used digital terrain analyses to identify sites best suited for riparian buffer and constructed wetland. Liu et al. (2009) developed an inexact linear programming model for optimal land use management to better protect water source and to gain maximum benefits from development. However Tomer and Liu's researches were operated only at the watershed and sub-watershed scale. As we can see there is an effective buffer zone for NPS pollutants in which the 
relationship between land use and water quality is the most strong and the placement of BMPs can optimize their effectiveness. This study demonstrated BMPs should be placed within $20 \sim 40 \%$ buffer sizes as in series following the urban storm runoff rout in Hanyang District, China. Watershed approach has been used widely to manage water quality and quantity within specific drainage area or watershed; the buffer zone can be used to improve environmental protection agencies and managers' effectiveness. NPS pollution controlling planning and management in Hanyang can chose the way of integration of watershed approach with effective buffer zone to realize control goals. Consequently economical and environmental benefits can be realized through this approach.

\section{Conclusions}

We explored the relationship between land use and water quality in buffers at various spatial scales. We concluded that not only proportion of land use but also its spatial pattern moderated land use effects on water quality. By proposing a dynamic complex hypothesis, we further described the impact of land use types, land use proportions, and land use patterns on water quality. The impact of land use on water quality is stronger in the effective buffer than that in the catchments or watershed. Buffer analysis can provide a way to determine the effective buffer width. And our study indicated that the identification of the effective buffer zones could provide new information and ideas for planning and management.

Acknowledgements This research was supported financially by the State Key Project on Fundamental Studies (973) (2007CB407307), and the Innovation Group Program of National Natural Science Foundation of China (40621061).

\section{References}

Alberti M, Booth D, Hill K, Coburn B, Avolio C, Coe S, Spirandelli D (2007) The impact of urban patterns on aquatic ecosystems: an empirical analysis in Puget lowland sub-basins. Landscape Urban Plan 80(4):345-361

Amiri BJ, Nakane K (2009) Modeling the linkage between river water quality and landscape metrics in the Chugoku District of Japan. Water Resour Manag 23(5):931-956

Bannerman RT, Owens DW, Dodds RB, Hornewer NJ (1993) Sources of pollutants in Wisconsin stormwater. Water Sci Technol 28(3-5):241-259

Basnyat P, Teeter LD, Lockaby BG (1999) Relationships between landscape characteristics and nonpoint source pollution inputs to coastal estuaries. Environ Manage 23(4):539-549

Basnyat P, Teeter LD, Lockaby BG, Flynn KM (2000) The use of remote sensing and GIS in watershed level analyses of non-point source pollution problems. Forest Ecol Manag 128:65-73

Brezonik PL, Stadelmann TH (2002) Analysis and predictive models of stormwater runoff volumes, loads, and pollutant concentrations from watersheds in the Twin Cities metropolitan area, Minnesota, USA. Water Res 36(7):1743-1757

Cao WZ, Bowden WB, Davie T, Fenemor A (2009) Modelling impacts of land cover change on critical water resources in the Motueka river catchment, New Zealand. Water Resour Manag 23(1):137-151

Chang HJ (2008) Spatial analysis of water quality trends in the Han River basin, South Korea. Water Res 42:3285-3304

Changnon SA, Demissie M (1996) Detection of changes in streamflow and floods resulting from climate fluctuations and land-use drainage changes. Climatic Change 32:411-421 
Conway TM, Lathrop RG (2005) Alternative land-use regulations and environmental impacts: assessing future land-use in an urbanizing watershed. Landscape Urban Plan 71:1-15

Donohue I, McGarrigle ML, Mills P (2006) Linking catchment characteristics and water chemistry with the ecological status of Irish rivers. Water Res 40(1):91-98

EPA China (2002) GB3838-2002. Available on: http://www.sepa.gov.cn/image20010518/3391.pdf (in Chinese, accessed 15 Aug 2008)

ESRI (2001) ArcGIS 8.1. Environmental Systems Research Institute Inc., Redlands, California

Fang JY, Rao S, Zhao SQ (2005) Human-induced long-term changes in the lakes of the Jianghan Plain, Central Yangtze. Front Ecol Environ 3(4):186-192

Foley JA, Ruth D, Asner GP et al (2005) Global consequences of land use. Science 309:570-574

Gburek WJ, Folmar GJ (1999) Flow and chemical contributions to streamflow in an upland watershed: a baseflow survey. J Hydrol 217:1-18

Gillies RR, Box JB, Symanzik J, Rodemaker EJ (2003) Effects of urbanization on the aquatic fauna of the Line Creek watershed, Atlanta-a satellite perspective. Remote Sens Environ 86: $411-422$

Grassland, Soil \& Water Research Laboratory (2001). Soil \& Water Assessment Tool. Available on: http://www.brc.tamus.edu/swat/soft_model_2000soft.html (accessed 20 May 2009)

Grimm NB, Faeth SH, Golubiewski NE, Redman CL, Wu JG, Bai XM, Briggs JM (2008) Global change and the ecology of cities. Science 319:756-760

Gustafson EJ (1998) Quantifying landscape spatial pattern: what is the state of the art? Ecosystems $1: 143-156$

Ha HJ, Stenstrom MK (2003) Identification of land use with water quality data in stormwater using a neural network. Water Res 37(17):4222-4230

Hanratty MP, Stefan HG (1998) Simulating climate change effects in a Minnesota agricultural watershed. J Environ Qual 27:1524-1532

Hunsaker CT, Levine DA (1995) Hierarchical approaches to the study of water quality in rivers. BioScience 45:193-202

Johnson LB, Richards C, Host GE, Arthur JW (1997) Landscape influences on water chemistry in Midwestern stream ecosystems. Freshwater Biol 37:193-208

Kim G, Choi E, Lee D (2005) Diffuse and point pollution impacts on the pathogen indicator organism level in the Geum River, Korea. Sci Total Environ 350:94-105

Leitch C, Harbor J (1999) Impacts of land-use change on freshwater runoff into the near-coastal zone, Holetown Catchments, Barbados: comparisons of long-term to single-storm effects. J Soil Water Conserv 3:584-592

Liu Y, Yu YJ, Guo HC, Yang PJ (2009) Optimal land-use management for surface source water protection under uncertainty: a case study of Songhuaba Watershed (Southwestern China). Water Resour Manag 23(10):2069-2083

Mander U, Kull A, Tamm V, Kuusemets V, Karjus R (1998) Impact of climatic fluctuations and land use change on runoff and nutrient losses in rural landscape. Landscape Urban Plan 41:229238

Mattikalli NM, Richards KS (1996) Estimation of surface water quality changes in response to landuse change: application of the export coefficient model using remote sensing and geographical information system. J Environ Manage 48:263-282

McGarigal K, Marks BJ (1995) FRAGSTATS: spatial pattern analysis program for quantifying landscape structure. Forest Science Department, Oregon State University, Corvallis

Mehaffey MH, Nash MS, Wade TG et al (2005) Linking land cover and water quality in New York City's water supply watersheds. Environ Monit Assess 107:29-44

Moreno JL, Navarro C, De Las Heras J (2006) Abiotic ecotypes in south-central Spanish rivers: reference conditions and pollution. Environ Pollut 143:388-396

O'Neill RV, Hunsaker CT, Jones KB, Riitters KH, Wickham JD, Schwartz PM, Goodman IA, Jackson BL, Baillargeon WS (1997) Monitoring environmental quality at the landscape scale. BioScience 47(8):513-519

Palmer M, Bernhardt E, Chornesky E et al (2004) Ecology for a crowded planet. Science 304:12511252

Phillips JD (1989) Evaluation of North Carolina's estuarine shoreline area of environmental concern from a water quality perspective. Coastal Manage 17:103-117

Rai SE, Sharma E (1998) Comparative assessment of runoff characteristics under different land-use patterns within a Himalayan watershed. Hydrol Process 12:2235-2248

Ren WW, Zhong Y, Meligrana J, Anderson B, Watt WE, Chen JK, Leung HL (2003) Urbanization, land use, and water quality in Shanghai 1947-1996. Environ Int 29(5):649-659 
Sawyer JA, Stewart PM, Mullen MM, Simon TP, Bennett HH (2004) Influence of habitat, water quality, and land use on macro-invertebrate and fish assemblages of a southeastern coastal plain watershed, USA. Aquat Ecosyst Health 7(1):85-99

Sieker H, Klein M (1998) Best management practices for stormwater runoff with alternative methods in a large urban catchment in Berlin, Germany. Water Sci Technol 38(10):91-97

Shao M, Tang XY, Zhang YH, Li WJ (2006) City clusters in China: air and surface water pollution. Front Ecol Environ 4(7):353-361

Sliva L, Williams DD (2001) Buffer zone versus whole catchment approaches to studying land-use impact on river water quality. Water Res 35(14):3462-3472

Sonzogni WC (1980) Pollution from land runoff. Environ Sci Technol 14(2):148-153

Tang Z, Engel BA, Pijanowski BC, Lim KJ (2005) Forecasting land use change and its environmental impact at a watershed scale. J Environ Manage 76(1):35-45

Tomer MD, as Principal Investigator (2002) Optimizing the placement of practices that improve water quality within a watershed. Research Project 01-024-Final Report. USDA/ARS-National Soil Tilth Laboratory

Tong STY, Chen WL (2002) Modeling the relationship between land-use and surface water quality. J Environ Manage 66:377-393

Tsihrintzis VA, Hamid R (1998) Runoff quality prediction from small urban catchments using SWMM. Hydrol Process 12:311-329

Van Dessel W, Van Rompaey A, Poelmans L, Szilassi P (2008) Predicting land cover changes and their impact on the sediment influx in the Lake Balaton catchment. Landscape Ecol 23(6): $645-656$

Wang X (2001) Integrating water-quality management and land-use planning in a watershed context. J Environ Manage 61:25-36

Wiens JA (2002) Riverine landscapes: taking landscape ecology into the water. Freshwater Biol 47(4):501-515 